\title{
Redução dos serviços de transporte rodoviário de passageiros e sua reativação na Colômbia durante a pandemia de covid-19
}

\author{
Fredy CAMILO García MORENO ${ }^{*}$
}

\section{RESUMO}

A pandemia de coronavírus covid-19 gerou uma emergência sanitária e a declaração de um estado constitucional de emergência econômica, social e ecológica na Colômbia, o que permitiu ao governo expedir um conjunto de normas que buscavam oferecer soluções aos diversos problemas gerados por esta situação. Este artigo procura explicar o ocorrido nos serviços de transporte rodoviário de passageiros e terminais rodoviários de transporte na Colômbia durante este período até o momento.

Palavras-chave: Covid-19, transporte rodoviário, terminais rodoviários, transporte coletivo de passageiros e mobilidade.

\section{DISMINUCIÓN DE SERVICIOS DE TRANSPORTE INTERURBANO Y SU REACTIVACIÓN EN COLOMBIA DURANTE LA PANDEMIA DEL COVID-19}

\section{RESUMEN}

La pandemia por covid-19 generó una emergencia sanitaria y la declaratoria de un Estado constitucional de emergencia económica, social y ecológica en Colombia, lo que permitió al gobierno expedir un conjunto de normas que buscaron dar soluciones

1 Advogado e Mestre em Direito com ênfase em Direito Econômico pela Universidade Externado da Colômbia, Especialista em Governo e Políticas Públicas pela Universidade de los Andes e pós-graduado em Logística e Transporte pela Universidade de Miami.

* DOI: https://doi.org/10.18601/01236458.n55.12 
a los distintos problemas generados por esta situación. Este artículo pretende explicar lo sucedido en los servicios de transporte interurbano y las terminales de transporte en Colombia durante este periodo hasta la fecha.

Palabras clave: covid-19, transporte interurbano, terminales de transporte, transporte colectivo de pasajeros por carretera y movilidad.

\section{REDUCTION OF INTERCITY BUS SERVICES AND THEIR REACTIVATION IN COLOMBIA DURING THE COVID-19 PANDEMIC}

\section{ABSTRACT}

The covid-19 pandemic generated a health emergency and a declaration of a constitutional state of economic, social, and ecological emergency in Colombia. This allowed the government to issue a set of rules that sought to offer solutions to the various problems generated by this situation. This article seeks to explain what has happened in motor coach transportation services and bus terminals in Colombia during this period of crisis.

Keywords: Covid-19, motor coach service, bus terminal, intercity bus services and mobility.

\section{INTRODUÇÃO}

A razão deste artigo é fornecer uma breve explicação dos desafios que a pandemia covid-1 $19^{[2]}$ teve para o transporte rodoviário de passageiros, especificando o objeto de uma perspectiva econômica que entende o serviço como um mercado, onde o Estado teve que restringir a oferta para atingir seus objetivos relacionados à saúde pública.

O direito à mobilidade sofre sérios desafios com a pandemia de coronavírus covid-19. No que se refere ao transporte de passageiros, a sua necessidade é evidente, pois é o mecanismo que permite a muitas pessoas a prestação de serviços em atividades essenciais para a sociedade; ao mesmo tempo, a sua restrição pode ser desejável, na medida em que, para evitar a propagação do vírus, optou-se por restringir a utilização de veículos, nomeadamente de serviço público, procurando evitar o contágio nesses espaços.

2 De acordo com a Organização Mundial da Saúde o coronavírus é "[...] COVID-19 é a doença infecciosa causada pelo coronavírus mais recentemente descoberta. Tanto esse novo vírus quanto a doença que ele causa eram desconhecidos antes do surto em Wuhan, China, em dezembro de 2019. Atualmente, o COVID-19 é uma pandemia que afeta muitos países ao redor do mundo [...]", Recuperado a partir de https://www.who.int/es/emergencies/diseases/novel-coronavirus-2019/advice-for-public/q-a-coronaviruses 
O documento apresenta as respostas institucionais do regulador para conseguir, a partir das suas competências, reduzir os serviços de transporte de forma organizada, promovendo a continuidade do serviço para as pessoas excetuadas, disponibilizando também informação e soluções aos usuários.

Por fim, será explicada a forma como os serviços de transporte estão sendo reativados. Mesmo sem ter sido superada a emergência sanitária, há também uma mudança nas decisões sobre mobilidade onde, ao longo de alguns meses, passamos do isolamento preventivo obrigatório para um isolamento seletivo com distanciamento individual responsável.

\section{SAÚDE E MOBILIDADE EM TEMPOS DE COVID-19}

\section{Considerações gerais sobre autoridade e direito à saúde}

De acordo com a Constituição Política, as autoridades são instituídas para proteger a vida, os direitos e as liberdades dos cidadãos (Const., 1991, art. 2), especialmente das crianças (Const., 1991, art. 44) e dos idosos (Const., 1991, art. 46); onde os deveres de autocuidado (Const., 1991, art. 49) e de solidariedade social (Const., 1991, art. 95) são essenciais para dar um marco constitucional a este estudo.

Nossa constituição estabelece o direito fundamental de circular livremente pelo território nacional, sem que seja um direito absoluto, pois pode-se ter limitações (Const., 1991, art. 24). As limitações, como expressão do controle da ordem pública, assentam no poder de polícia do Presidente da República (Const., 1991, art. 189-4), que prevalece no território nacional (Const., 1991, art. 296). Nas entidades territoriais cabe aos governadores e aos prefeitos exercerem a função de polícia (Const., 1991, art. 303 e 315-2).

A autoridade policial do Presidente da República, dos governadores e dos prefeitos está consagrada no artigo 198 da Lei 1801 de 2016. O presidente exerce a função policial $^{3}$ para a garantia dos direitos, liberdades públicas e deveres, garantindo a coexistência em território nacional, e dá instruções aos prefeitos (Lei 1801, 2016, art. 205) e governadores (Lei 1801, 2016, art. 201) para preservar e restaurar esta coexistência (Lei 1801, 2016, art. 199).

O direito à saúde, consagrado em lei estatutária, explica que compete ao Estado proteger e garantir o gozo efetivo do direito fundamental a esta, (Lei 1751, 2015, art. 5), além de o dever de autocuidado e solidariedade com a família e também com a comunidade (Lei 1751, 2015, art. 10-a e 10-c).

3 A função de polícia administrativa a que se refere este artigo é definida como a atribuição e exercício de competências por parte das autoridades, a qual é sempre exercida nos parâmetros da Lei. Para o efeito, pode ser consultada a sentença C-813-14 do Tribunal Constitucional da Colômbia. 


\section{Serviços de transportes rodoviários de passageiros em condições normais}

Os serviços de transportes rodoviários de passageiros são regulados pelo Decreto 1079 de $2015^{[4]}$ e estão sujeitos a autorizações concedidas pelo Estado como um desenvolvimento da Lei 336 de 1996. Os serviços de terminais rodoviários de transporte ${ }^{5}$ também são regidos pelo mesmo decreto e são considerados um serviço relacionado e público.

Tendo em conta esta ligação, é importante compreender o serviço de transporte como um processo que envolve tanto terminais de transporte como empresas de transporte que, individualmente desenvolvem atividades, que em conjunto permitem a prestação do serviço público.

Em condições normais, a operação permite que os usuários se desloquem de um município a outro, sendo a utilização de terminais de transporte obrigatória pelas empresas e usuários dos municípios onde se encontram. Nos municípios onde não existem terminais é a autoridade municipal quem determina a origem e o destino desses serviços.

\section{A chegada da pandemia}

A Organização Mundial da Saúde, OMS, declarou o coronavírus covid-19 como pandemia no dia 11 de março deste ano ${ }^{6}$, o que gerou medidas para mitigar o contágio. A fase de contenção, na Colômbia, teve início no dia 6 de março de 2020 quando foi confirmado o primeiro caso no país, assim, dentro da fase de contenção, no dia 20 de março do mesmo ano foi iniciada a quarentena para controlar a velocidade de proliferação de casos. A partir deste dia, os serviços de transporte rodoviários de passageiros foram restringidos.

A emergência sanitária decorrente do coronavírus covid-19 visava prevenir e controlar a disseminação do vírus, reduzindo assim o contágio, e foi decretada, inicialmente, até 30 de maio de 2020 (Resolução 385, 2020), sendo prorrogada até 31 de agosto de 2020 (Resolução 844, 2020) e, novamente prorrogada até 30 de novembro de 2020 (Resolução 1462, 2020).

4 A regulamentação do transporte terrestre de passageiros por rodovia encontra-se no Livro 2, Parte 2, Primeiro Título, Capítulo 4 do Decreto 1079 de 2015.

5 A definição de terminais rodoviários de transporte encontra-se no artigo 2.2.1.4.10.5 do Decreto 1079 de 2015.

6 Discurso de abertura do Diretor-Geral da OMS na conferência de imprensa sobre COVID-19 realizada em 11 de março de 2020, Recuperado a partir de https://www.who.int/es/dg/speeches/detail/ who-director-general-s-opening-remarks-at-the-media-briefing-on-covid-19_-11-march-2020 


\section{SERVIÇOS DE TRANSPORTE RODOVIÁRIO DE PASSAGEIROS E TERMINAIS RODOVIÁRIOS DE TRANSPORTE DURANTE A PANDEMIA}

Todas as restrições à mobilidade basearam-se no poder presidencial em matéria de ordem pública acima explicada, sendo inicialmente delineadas no Decreto 418 de 18 de março de 2020, sendo reiterada a aplicação preferencial dos mandatos do presidente sobre os dos governadores e prefeitos.

É de conhecimento público que, durante o período de isolamento, algumas autoridades territoriais, no uso das suas atribuições legais, decretaram medidas de restrição de movimentos, destinadas a atenuar ou controlar a propagação do coronavírus covid-19.

Em resposta a esta situação, o governo nacional estabeleceu, pelo decreto 420 de 18 de março de 2020, a restrição específica aos prefeitos e governadores de não impedir o serviço de transporte terrestre rodoviário de passageiros e o transporte de passageiros por fretamento e carga, sempre que estas modalidades fossem autorizadas pelas autoridades nacionais e correspondessem à prestação de um serviço público essencial.

Nesse sentido, a regulação do mercado dava garantias em matéria de transporte rodoviário de passageiros, o que indicava, particularmente, o poder presidencial à instrução precisa aos prefeitos e aos governadores para garantir um conjunto de atividades que deveriam ser asseguradas pelas transportadoras de passageiros, garantindo assim o serviço público estritamente necessário a eles relacionado.

O governo procurou responder aos desafios que este regulamento implicava, com base em um desenho institucional que melhorou os sistemas de informação a partir da sua centralização, em um Centro de Logística e Transporte (CLT) composto maioritariamente por diversos entes públicos, cujas funções principais eram o aconselhamento, decisão, racionalização e orientação das atividades de transporte.

Do ponto de vista dos custos de transação (Arias y Caballero, 2002) as decisões do CLT poderiam ser proferidas sem os procedimentos adequados que, em alguns casos, ordenam publicações e consultas a autoridades administrativas.

A regra estabelecida pelo Decreto 482 de 2020, para o transporte rodoviário de passageiros era permitir que seu serviço atendesse a população que se encontrava no âmbito das autorizações, reduzindo a oferta em até cinquenta por cento $(50 \%) \mathrm{da}$ capacidade de transporte autorizada (Decreto 482, 2020, art. 4-1). Quanto aos terminais rodoviários de passageiros, sua operação era permanente, sempre considerando a oferta de operações autorizadas pelo CLT.

O mais interessante sobre as regras estabelecidas pelo Decreto 482 de 2020 foi a premissa de explicar que não haveria penalidades para terminais rodoviários de passageiros caso houvesse a cessação da oferta de operação das empresas de transporte rodoviário de passageiros, nem para estas, pelo fato de reduzir o serviço autorizado em menos de cinquenta por cento $(50 \%)$ durante o período de emergência, o que introduziu um incentivo à continuidade dos serviços pelos regulados.

O Centro de Logística e Transporte foi criado com amplas competências, o que para o estudo de caso gerou a possibilidade de emitir regulamentos dirigidos aos 
agentes de mercado, comunicando aos usuários do setor as medidas que impactam na mobilidade, modificando a oferta de transporte terrestre intermunicipal e a atribuição temporária de itinerários.

Agora, além destas regras, o Decreto 569 de 2020 estabeleceu um prazo adicional para o direito de retratação dos usuários que haviam adquirido passagens, no momento da solicitação, durante o período da emergência sanitária em até um ano adicionais, garantindo assim o reembolso com serviços prestados pela mesma empresa.

Da mesma forma, este decreto estabelecia que o CLT concederia licenças para todos os serviços que são necessários à exploração do transporte, alguns inerentes à atividade operacional fixa, como os associados à manutenção de veículos ou peças sobressalentes, ou outros que são exigidos na operação e foram expressamente restritas, como restaurantes e hotéis.

\section{Intervenção no mercado do Centro de Logística e Transporte (CLT) ${ }^{7}$}

O funcionamento dos itinerários de transporte rodoviário de passageiros gerou um regime de rotas suburbanas, que o CLT definiu como aquelas dentro de um raio de ação de 40 quilômetros da principal cidade, permitindo a operação regular por meio do ajuste da oferta de ônibus à demanda existente de passageiros. Nestes casos, se existisse um terminal de transporte no município, os horários de chegada e saída tinham que ser coordenados com as empresas.

Para as rotas com raio de ação superior a 40 quilômetros entre o município de origem e destino foram estabelecidas regras de informação precisas, obrigando o terminal de transporte a disponibilizar linha telefônica aos usuários isentos, a fim de que os passageiros se inscrevessem 24 horas antes da viagem.

A oferta de viagens das transportadoras deveria ser informada ao terminal ou ao município, agendando apenas as viagens requeridas pelos usuários excluídos. Neste caso, a concorrência foi limitada e foi permitido um regime de autorregulação baseado na alternância de despachos de diferentes empresas autorizadas em uma rota, garantindo sempre condições de biossegurança.

A operação dos Terminais de Transporte Terrestre foi ajustada à oferta autorizada pelo Centro de Logística e Transporte, ficando os terminais que se localizavam em áreas suburbanas, definidas pelo Ministério dos Transportes e homologadas pelo CLT, a que não poderiam suspender o uso das instalações físicas. Nos terminais em operação, o uso das instalações por acompanhantes foi restrito, exceto para pessoas com deficiência ou menores.

7 O Centro de Logística e Transporte emitiu documentos dirigidos às empresas de transporte rodoviário de passageiros e terminais rodoviários de transporte com um conjunto de instruções que dão suporte a este capítulo. Resumidamente, pretende-se explicar o funcionamento deste mercado durante a pandemia. 
Os terminais de transporte também foram encarregados de realizar campanhas de informação, visando o acesso do usuário ao serviço e à reserva de bilhetes, onde foram promovidas as compras online.

\section{INTERVENÇÃO NO MERCADO DE TRANSPORTE RODOVIÁRIO DE PASSAGEIROS}

O mercado de transportes rodoviário de passageiros foi intervencionado pelo governo nacional, em particular pelo Ministério dos Transportes, com medidas que foram coordenadas principalmente a partir do Centro de Logística e Transportes, o que significou um novo arranjo institucional (Fiani, 2016), o qual promoveu uma regulação eficiente que diminuiu custos de transação, especialmente do contrato de ransporte.

Em um momento histórico sem precedentes, como é a pandemia de covid-19, a regulação econômica (Guinard-Hernández, 2017) serviu como um instrumento para promover a eficiência na prestação do serviço público de transporte intermunicipal, melhorar a qualidade do serviço, garantir a primazia do consumidor e a criação de uma agência especializada que faltava no setor. Foi uma medida notável.

No momento em que ocorreram os encerramentos, foi criada uma nova realidade em contraposição à "normalidade", onde se distinguem três grupos de pessoas: primeiro aquelas que se encontravam dentro das atividades permitidas e excetuadas da restrição de mobilidade, porque seu trabalho estava relacionado a serviços essenciais, principalmente ligados à saúde, serviços públicos e cadeia de suprimentos; em segundo lugar, aqueles que, ao ver o término de suas atividades laborais, acadêmicas ou sociais, tiveram que retornar ao seu local de origem ou chegar a um local que permitisse seu bem-estar no período de isolamento; e, em terceiro, aqueles que por força maior tiveram que se deslocar em tempos de pandemia.

Uma clara manifestação de eficiência foi a forma como, no início da pandemia, buscou-se restringir a demanda sem reduzi-la definitivamente, garantindo a continuidade dos serviços aos excluídos, para isso, foram introduzidos incentivos (Rubio, 2001) nas regulamentações a partir da ameaça ou punição. Eles chamaram a atenção dos provedores que, como o restante da população, temiam pela ameaça de contágio por um vírus como o covid-19.

Depois, para promover esta eficiência, facilitou acordos comerciais entre transportadoras e ordenou a sua articulação com os terminais de transporte, o que é excepcional, visto que, como regra geral, compete às empresas organizar os fatores de produção para o uso adequado da infraestrutura (García, 2015).

Por fim, o direito de retratação (Pabón y Mora, 2014), pouco conhecido no ramo do transporte rodoviário de passageiros, passou a ser uma defesa do consumidor, que diante da pandemia alterou a programação de suas viagens de forma inesperada, avançando assim sua posição perante a empresa, no âmbito de um contrato de adesão. 
Nesse sentido, o governo também deu à empresa a possibilidade de ressarcir os serviços que ela mesma gera, o que facilitará o acordo entre as partes.

\section{REATIVAÇÃO DO MERCADO DE TRANSPORTE RODOVIÁRIO DE PASSAGEIROS}

Com o Decreto 1168 de 2020, a Colômbia entrou em uma fase diferente, chamada de isolamento seletivo e distanciamento individual responsável, que é regido pelo autocuidado, o que implica uma abertura das atividades econômicas com cumprimento de protocolos de biossegurança para esses fins. A exceção a esta regra geral é a restrição de mobilidade com autorização do Ministério do Interior, em municípios altamente afetados pela covid-19.

Após vários meses em que a regra era listar um conjunto de atividades permitidas, o estado de nova "normalidade" restringe pontualmente algumas atividades que envolvam assembleias de massa, que só podem ser desenvolvidas com planos-piloto estritos. A partir da entrega deste artigo, estamos apenas conhecendo este novo cenário.

A geração de novas obrigações para os agentes de mercado, no marco da pandemia, promoveu a utilização de canais digitais de venda de bilhete de passagem, a utilização de aplicativos como o Coronapp ${ }^{8}$ para monitoramento do estado de saúde, além de redes sociais para comunicar os destinos e preços oferecidos no mercado de transporte terrestre de passageiros.

O transporte rodoviário de passageiros e os terminais de transporte encontram-se em um cenário de reativação, em um momento em que a economia sofre graves problemas $^{9}$, sendo que os hábitos de teletrabalho e de estudo em meios virtuais se impõem como regra geral, razões que sugerem que a recuperação da demanda será lenta.

Os protocolos de biossegurança para o setor de transporte foram atualizados por meio da Resolução 0001537 de 2 de setembro de 2020 do Ministério da Saúde, mas como o serviço está atuando, implantando protocolos, nos cinco meses anteriores à sua expedição, tanto as empresas de transporte rodoviário de passageiros como os terminais rodoviários têm experiência na sua implementação, no entanto, é necessário que essas informações sejam transmitidas aos usuários para criar confiança nas viagens.

No que se refere às assimetrias de informação que foram apresentadas em relação à oferta, aos mecanismos de obrigatoriedade de publicação dos serviços e aos preços oferecidos pelas empresas transportadoras, também foram acompanhadas pela Superintendência dos Transportes, entidade que exige que os empresários informem o preço das passagens, nos termos da regulamentação em vigor.

8 Coronapp é um aplicativo criado pelo Ministério da Saúde da Colômbia para fazer o autodiagnóstico do coronavírus covid-19.

9 De acordo com o Fundo Monetário Internacional, a economia colombiana vai contrair 7,8 \% em 2020 . 


\section{CONCLUSÕES}

Atualmente, a pandemia gerada pelo coronavírus covid-19 continua sendo um risco latente para a humanidade, sem haver uma solução que permita o retorno das condições de "normalidade" que existiam antes de sua chegada.

Nos primeiros dias de isolamento preventivo obrigatório na Colômbia, um dos principais desafios do Estado foi a prestação de serviços de transporte público terrestre para garantir a conectividade do território e a mobilidade das pessoas isentas.

Um aspecto digno de nota da análise dos decretos legislativos do Ministério do Interior, relacionados com as regras do isolamento preventivo obrigatório e do isolamento seletivo em vigor, é a reiterada indicação do poder central em matéria de aplicação das regras de ordem pública, exercidas pelo presidente, com prevalência sobre o mesmo poder que os prefeitos e governadores têm.

O Centro de Logística e Transporte é uma ferramenta de intervenção econômica no mercado, a partir de um novo desenho institucional. Este continuará a funcionar durante as emergências de saúde atuais e futuras, por isso, é aconselhável aprofundar a análise dos resultados das suas decisões através de uma avaliação ex-post.

A intervenção do Estado na organização dos serviços de transporte, coordenando a atividade das empresas transportadoras e terminais rodoviários de passageiros, gerou eficiência na prestação dos serviços, eliminou custos de transação no contrato de transporte e proporcionou melhorias no controle da operação.

A pandemia acelerou o acesso dos usuários às informações, principalmente em relação ao conteúdo do contrato de transporte, incluindo o direito de retratação. Esta modernização do consumo não só vai melhorar as relações contratuais graças ao maior número de informação, mas também vai permitir uma melhor gestão dos processos de venda e embarque, o que reduz as interações e, portanto, é desejável para evitar a expansão do vírus.

Os desafios da reativação do mercado de transporte terrestre de passageiros são importantes devido à difícil conjuntura econômica, porém, a pandemia acelerou a chegada de tecnologia ao setor em termos de marketing de passagens e preparação de viagens. Nesse sentido, fica evidente a necessidade de estabelecer canais de comunicação que permitam explicitar os protocolos de biossegurança de forma a proporcionar confiança aos usuários.

\section{BIBLIOGRAFIA}

Arias, X., \& CABAlLero, G. (2002). Instituciones, costos de transacción y políticas públicas: un panorama. Revista de Economía Institucional. https://revistas.uexternado.edu.co/ index.php/ecoins/article/view/207/3323

Constitución Política de Colombia. (1991).

Congreso de la República de Colombia. (20 de dezembro de 1996), Estatuto General del Transporte [Ley 336 de 1996]. DO: 42984. 
Congreso de la República de Colombia. (16 de fevereiro de 2015), Por medio de la cual se regula el derecho fundamental a la salud y se dictan otras disposiciones. [Ley $1751 \mathrm{de}$ 2015]. DO: 49427.

Congreso de la República de Colombia. (29 de julho de 2016), Código Nacional de Seguridad y Convivencia Ciudadana [Ley 1801 de 2016]. DO: 49949.

Corte Constitucional. (5 de novembro de 2014) Sentencia C-813-14.

FIANI, R. (2016). O problema dos custos de transação em parcerias público-privadas em infraestrutura. IPEA. http://repositorio.ipea.gov.br/bitstream/11058/7398/1/td_2261.PDF

Fondo Monetario Internacional [FMI]. (2020). Transcript of the Press Conference on the Regional Economic Outlook Update for Latin America \& the Caribbean. https://www. imf.org/en/News/Articles/2020/06/29/tr062620-transcript-press-conference-reo-updatelatin-america-and-the-caribbean

García Moreno, F. (2015). Regulación y fallas del mercado del transporte interurbano de pasajeros por carretera: un estudio desde el análisis económico del derecho. Con-Texto, (44), 9-35. https://doi.org/10.18601/01236458.n44.02

Guinard-HernándeZ, D. (2017). La "regulación económica" como instrumento de dirección estatal de la economía. Revista de Economía Institucional. https://revistas.uexternado.edu. co/index.php/Deradm/article/view/5010/6110

Ministerio de Salud y Protección Social. (12 de março de 2020). Por la cual se declara la emergencia sanitaria por causa del coronavirus COVID-19 y se adoptan medidas para hacer frente al virus. [Resolución 385 de 2020]. DO: 51284.

Ministerio de Salud y Protección Social. (27 de maio de 2020). Por la cual se prorroga la emergencia sanitaria por el nuevo Coronavirus que causa la COVID-19. [Resolución 884 de 2020]. DO: 51327.

Ministerio de Salud y Protección Social. (26 de agosto de 2020). Por la cual se prorroga la emergencia sanitaria por el nuevo Coronavirus que causa la Covid-19, se modifican las Resoluciones 385 y 844 de 2020 y se dictan otras disposiciones. [Resolución 1462 de 2020]. DO: 51418.

Ministerio de Transporte. (26 de maio de 2015). Decreto Único Reglamentario del Sector Transporte. [Decreto 1079 de 2015]. DO: 49523.

Ministerio de Transporte. (26 de março de 2020). Por el cual se dictan medidas sobre la prestación del servicio público de transporte y su infraestructura, dentro del Estado de emergencia, económica, social y ecológica. [Decreto 482 de 2020]. DO: 51268.

Ministerio de Transporte. (15 de abril de 2020). Por la cual se adoptan medidas sobre la prestación del servicio público de transporte y su infraestructura, dentro del Estado de emergencia, económica, social y ecológica. [Decreto 569 de 2020]. DO: 51286.

Ministerio del Interior. (18 de março de 2020). Por el cual se dictan medidas transitorias para expedir normas en materia de orden público. [Decreto 418 de 2020]. DO: 51260.

Ministerio del Interior. (18 de março de 2020). Por el cual se imparten instrucciones para expedir normas en materia de orden público en virtud de la emergencia sanitaria generada por la pandemia de COVID-19. [Decreto 420 de 2020]. DO: 51260. 
Ministerio del Interior. (22 de março de 2020). Por el cual se imparten instrucciones en virtud de la emergencia sanitaria generada por la pandemia del coronavirus Covid-19 y el mantenimiento del orden público. [Decreto 457 de 2020]. DO: 51264.

Ministerio del Interior. (8 de abril de 2020). Por el cual se imparten instrucciones en virtud de la emergencia sanitaria generada por la pandemia del Coronavirus COVID-19, y el mantenimiento del orden público. [Decreto 531 de 2020]. DO: 51282.

Ministerio del Interior. (24 de abril de 2020). Por el cual se imparten instrucciones en virtud de la emergencia sanitaria generada por la pandemia del Coronavirus COVID-19, y el mantenimiento del orden público. [Decreto 593 de 2020]. DO: 51295.

Ministerio del Interior. (6 de maio de 2020). Por el cual se imparten instrucciones en virtud de la emergencia sanitaria generada por la pandemia del Coronavirus COVID-19, y el mantenimiento del orden público. [Decreto 636 de 2020]. DO: 51306.

Ministerio del Interior. (28 de maio de 2020). Por el cual se imparten instrucciones en virtud de la emergencia sanitaria generada por la pandemia del Coronavirus COVID-19, y el mantenimiento del orden público. [Decreto 749 de 2020]. DO: 51328.

Ministerio del Interior. (9 de julho de 2020). Por el cual se imparten instrucciones en virtud de la emergencia sanitaria generada por la pandemia del Coronavirus COVID-19, y el mantenimiento del orden público. [Decreto 990 de 2020].

Ministerio del Interior. (28 de julho de 2020). Por el cual se imparten instrucciones en virtud de la emergencia sanitaria generada por la pandemia del Coronavirus COVID-19, y el mantenimiento del orden público. [Decreto 1076 de 2020].

Ministerio del Interior. (25 de agosto de 2020). Por el cual se imparten instrucciones en virtud de la emergencia sanitaria generada por la pandemia del Coronavirus COVID-19, y el mantenimiento del orden público. [Decreto 1168 de 2020].

Pabón Almanza, C., \& Mora Ramírez, A. (2014). Límites al ejercicio abusivo del derecho de retracto. Inconstitucionalidad en la sobreprotección del consumidor. Con-Texto, (41), 67-86. https://revistas.uexternado.edu.co/index.php/contexto/article/view/3853

Rubio, M. (2001). Premios y castigos: una caricatura de los sistemas normativos. Con-Texto, (11), 4-48. https://revistas.uexternado.edu.co/index.php/contexto/article/view/1774

Organización Mundial de la Salud [OMS]. (2020). Alocución de apertura del Director General de la OMS en la rueda de prensa sobre la COVID-19 celebrada el 11 de marzo de 2020. https://www.who.int/es/dg/speeches/detail/who-director-general-s-opening-remarks-atthe-media-briefing-on-covid-19-11-march-2020 